\title{
INFLUENCIA DO CONCEITO NEUROEVOLUTIVO BOBATH NO TÔNUS E FORÇA MUSCULAR E ATIVIDADES FUNCIONAIS ESTÁTICAS E DINÂMICAS EM PACIENTES DIPARÉTICOS ESPÁSTICOS APÓS PARALISIA CEREBRAL
}

\author{
Influence of Bobath neuronal evolution concept in the muscle tonus and strength, static and \\ dynamics functional activities in diparetic spatic patients after cerebral palsy
}

Lívia Willemann Peres ${ }^{1}$, Aneline Maria Ruedell ${ }^{2}$ e Cristina Diamante ${ }^{3}$

\begin{abstract}
RESUMO
O objetivo desta pesquisa foi observar o tônus e a força muscular, juntamente com atividades funcionais estáticas e dinâmicas após tratamento por meio do Conceito Neuroevolutivo Bobath, em pacientes diparéticos espásticos devido a Paralisia Cerebral. Participaram do estudo quatro pacientes diparéticos espásticos com idade entre 6 a 8 anos, avaliados antes e após o tratamento. Avaliou-se o tônus muscular pela Escala de Ash Worth modificada e as atividades funcionais estáticas e dinâmicas e a força muscular. A pesquisa realizou-se na Clínica escola de Fisioterapia da Universidade do Oeste do Paraná, durante três meses. O tratamento constituiu-se de 25 sessões, duas vezes por semana com duração de 40 minutos. Houve uma diminuição do tônus e aumento da força muscular em grupos musculares específicos em todos os pacientes. Ainda verificou-se adequação em algumas atividades funcionais estáticas e dinâmicas. Conclui-se que o tratamento aplicado nestes pacientes proporcionou uma diminuição de tônus e aumento de força muscular, e conseqüente melhora nas atividades funcionais estáticas.

Palavras chave: Paralisia Cerebral, força muscular, tônus muscular, Conceito Bobath.

\section{SUMMARY}

The objective of this research was to observe the muscle tonus and strength together with the functional activities, after treatment by Bobath neuronal evolution concept, in diparetic spatic patients after cerebral palsy. Four diparetic spatic patients, aging from 6 to 8 years old, were evaluated before and after treatment. The muscle tonus, the static and dynamics functional activities and muscle strength were assessed by the modified Ashworth Scale. The research took place in the School Clinic of Physical Therapy of Universidade do Oeste do Paraná for three months. The treatment consisted of 25 sessions of 40 minutes, twice a week. There was a decrease in the tonus and an increase in muscle strength in specific muscle groups in all patients. Adequacy was also found in some static and dynamics functional activities. It can be concluded that the treatment in these patients provided a decrease in muscle tonus and an increase in muscle strength, and consequently an improvement in static functional activities.
\end{abstract}

Keywords: cerebral palsy, muscle strength, muscle tonus, Bobath concept.

${ }^{1}$ Pós graduada em fisioterapia clínica com ênfase em pediatria pela Universidade Estadual do Oeste do Paraná (UNIOESTE). ${ }^{2}$ Docente auxiliar de fisioterapia em pediatria; Universidade Estadual do Oeste do Paraná (UNIOESTE), Cascavel, PR; mestranda do programa de pós-graduação da Universidade Federal de Santa Maria (UFSM), Santa Maria, RS.

${ }^{3}$ Docente assistente de fisioterapia preventiva; Universidade Estadual do Oeste do Paraná (UNIOESTE), Cascavel, PR; mestre em engenharia de produção. 


\section{INTRODUÇ̃̃O}

A paralisia cerebral (PC) é definida como uma alteração da postura e do movimento, permanente, mas não imutável. Resulta de um distúrbio no cérebro não progressivo, devido a fatores hereditários, eventos ocorridos durante a gravidez, parto, período neonatal ou durante os primeiros dois anos de vida ${ }^{1}$.

A diparesia espástica é o principal tipo de paralisia cerebral em crianças recém-nascidas pré-termo. O exame clínico destas crianças revela fraqueza muscular, déficit de controle motor e espasticidade nos membros inferiores, com déficit nas habilidades motoras finas 2,3 .

Lesões hemorrágicas como a leucomálacia periventricular podem provocar o quadro clínico de diparesia espástica que afeta principalmente membros inferiores. Admite-se que um fator de grande importância patogênica seja a degeneração cística grave da substância branca. A gravidade do distúrbio motor parece manter relação com a extensão das anomalias reveladas pela tomografia computadorizada ${ }^{4}$.

A abordagem fisioterapêutica na PC teria a finalidade de preparar a criança para uma função, manter ou aprimorar as já existentes, atuando sempre de forma a adequar a espasticidade. Entretanto, o prognóstico da paralisia cerebral depende evidentemente do grau de dificuldade motora, da intensidade de retrações e deformidades esqueléticas e da disponibilidade e qualidade da reabilitação ${ }^{5}$.

Um dos métodos para tratamento de crianças com PC é o conceito Bobath que tem por objetivo incentivar e aumentar a habilidade da criança de mover-se funcionalmente da maneira mais coordenada possível. Os movimentos normais não podem ser obtidos se a criança permanecer em algumas posições e se mover de uma maneira limitada ou incoordenada, por inadequação do tônus postural anormal e incoordenação de postura e movimento presentes nestas crianças ${ }^{6}$.

O conceito Bobath parte do princípio de manuseios nos quais utilizamos padrões que irão influenciar o tônus muscular, pois, através dos pontos chaves de controle, estaremos produzindo mudanças no tônus muscular. Isto, conseqüentemente, irá influenciar o controle postural e o desempenho das atividades funcionais. A mudança de tônus, por sua vez, influenciará as características neurais e não neurais ${ }^{6}$.

Em longo prazo, a capacidade da criança em usar as habilidades que estão sendo facilitadas, dependerá da condição do sistema nervoso central (SNC) em adaptar-se a essas mudanças, incluindo a capacidade perceptiva e cognitiva do paciente no uso destas habilidades em um contexto ${ }^{7}$.

Estes fatores justificam a execução desta pesquisa, que apresenta como objetivo observar o tônus, força muscular e atividades funcionais estáticas e dinâmicas antes e após o tratamento fisioterapêutico com o Conceito Neuroevolutivo Bobath.

\section{MATERIAIS E MÉTODOS}

Este trabalho é derivado de um projeto de pesquisa aprovado pelo comitê de ética da Universidade Estadual do Oeste do Paraná - UNIOESTE (parecer 284/2007), desenvolvidos no ano de 2007, como pré-requisito para obtenção do título de pós-graduação.

A pesquisa realizada é do tipo quanti-qualitativo com corte longitudinal, de caráter explicativo segundo os objetivos da pesquisa. $\mathrm{O}$ universo estudado foi de pacientes diparéticos após paralisia cerebral, as quais foram avaliados antes e após o tratamento por meio do conceito neuroevolutivo Bobath. Os itens avaliados foram: tônus muscular conforme Ash Worth ${ }^{8}$, avaliação da força ${ }^{9}$, atividades funcionais de acordo com Durigon \& Sá ${ }^{10}$. O presente estudo realizou-se na Clínica de Fisioterapia da Universidade Estadual do Oeste do Paraná (UNIOESTE), no setor de pediatria.

Foram selecionados quatro voluntários, sendo três do gênero masculino e um do gênero feminino com idade de 06 a 08 anos, com diagnóstico de diparesia espástica moderada a leve, após Paralisia Cerebral. Para seleção da amostra os responsáveis pelos voluntários receberam um termo de consentimento livre esclarecido, para ser lido e assinado concordando em participar do estudo.

Os critérios de inclusão foram: pacientes diparéticos espásticos após Paralisia Cerebral; com idade entre 06 a 08 anos de idade; assinatura do termo de consentimento livre e esclarecido devidamente preenchido e assinado; marcha com ou sem apoio; ausência de cirurgias ortopédicas por um período de seis meses. Os critérios de exclusão foram: o direito do voluntário de abandonar a pesquisa a qualquer momento, sem a necessidade de justificar, a não entrega do termo de consentimento livre e esclarecido devidamente preenchido e assinado; a recusa em participar do projeto por livre e espontânea vontade; e mais de três faltas consecutivas ao tratamento.

Os Procedimentos para coleta de dados foram:

1. Tônus e força

As medidas de tônus foram realizadas através da Escala de Ash Worth modificada ${ }^{8}$ que leva em conta a reação ao alongamento muscular. Aavaliação foi realizada com o paciente deitado em um tablado em diferentes decúbitos, dependendo do grupo muscular a ser testado. O paciente deveria estar vestindo roupas adequadas, que não impedissem a realização do movimento. A temperatura do ambiente deveria estar agradável para o paciente, em torno dos $25^{\circ} \mathrm{C}$, para não interferir no tônus muscular. Durante a avaliação, o examinador utilizava mobilização passiva e sem comandos verbais. Logo após, o avaliador define o escore de 0 a 4 , de acordo com o resultado apresentado pela criança, conforme quadro I. 
Quadro I - Escala de Ashworth modificada para avaliação do grau de espasticidade.

Fonte: Quagliato, 1998.

\begin{tabular}{|l|l|}
\hline GRAUS & \\
\hline 0 & Sem aumento do tônus muscular \\
\hline 1 & $\begin{array}{l}\text { Leve aumento do tônus muscular manifestando-se como um resistir e ceder ou por mínima resistência na extensão } \\
\text { máxima do movimento passivo. }\end{array}$ \\
\hline $1+$ & $\begin{array}{l}\text { Leve aumento do tônus muscular manifestando-se como uma resistência que persiste de maneira discreta através da } \\
\text { extensão do movimento remanescente (menos da metade deste). }\end{array}$ \\
\hline 2 & $\begin{array}{l}\text { Aumento do tônus mais acentuado durante a maioria da extensão do movimento, mas com facilidade de se mover o } \\
\text { segmento acometido. }\end{array}$ \\
\hline 3 & Aumento considerável do tônus muscular, com dificuldade na movimentação passiva. \\
\hline 4 & O segmento acometido está rígido em flexão, extensão, abdução e adução (etc). \\
\hline
\end{tabular}

Em relação a avaliação da força muscular, esta foi testada através da capacidade muscular de desenvolver tensão contra uma leve resistência manual exercida pelo examinador ou pelo movimento realizado pela criança contra a ação da gravidade. Inicialmente, a criança foi posicionada em prono ou supino de acordo com o grupo muscular que foi avaliado. Em seguida, o segmento articular próximo ao grupo muscular a ser avaliado foi estabilizado. $\mathrm{O}$ examinador realizou um movimento passivo com o membro inferior da criança, no intuito de demonstrar para ela como esta deveria fazer o movimento ativamente. Logo após, a criança voltou à posição inicial e realizou o movimento demonstrado anteriormente ${ }^{9}$.

Quadro I I - Teste de força muscular.

Fonte: Reese, 2000.

\begin{tabular}{|c|l|}
\hline Graus & \\
\hline 0 & nenhuma evidência de contração pela visão ou palpação; \\
\hline 1 & ligeira contração, nenhum movimento; \\
\hline 2 & Movimento através da amplitude completa na posição com gravidadeeliminada; \\
\hline 3 & Movimento através da amplitude completa contra a gravidade; \\
\hline 4 & Movimento através da amplitude completa contra a gravidade e capazde prosseguir contra uma resistência moderada; \\
\hline 5 & Movimento através da amplitude completa contra a gravidade e capazde prosseguir contra uma resistência máxima. \\
\hline
\end{tabular}

Os grupos musculares a serem testados foram: extensores, adutores e abdutores de quadris (na posição prono), flexores de quadril, plantiflexores, dorsiflexores, inversores e eversores de tornozelo (na posição supina).

1. Atividades Funcionais

As atividades funcionais foram avaliadas, através da escala de atividades funcionais estáticas e dinâmicas ${ }^{10}$. Na avaliação de atividades funcionais dinâmicas (engatinhar e marcha), foram considerados os parâmetros quantitativos e qualitativos. Para o parâmetro quantitativo foi observada a capacidade de realização da atividade e, como parâmetro qualitativo, a presença ou ausência de normalidade no padrão de realização.

Quadro III - Escala de Avaliação das Atividades Funcionais Dinâmicas (engatinhar e marcha) desenvolvida para a amostra de crianças com Paralisia Cerebral.

Fonte: Durigon e Sá (2004)

\begin{tabular}{|c|l|}
\hline GRAU & Realização da atividade funcional \\
\hline 0 & Não realiza a atividade funcional \\
\hline 1 & Realiza a atividade em padrão anormal \\
\hline 2 & Realiza a atividade em padrão normal e coordenado, porém com alterações qualitativas. \\
\hline
\end{tabular}


Para a avaliação das atividades funcionais estáticas, as crianças foram orientadas a adotarem as seguintes posturas: sedestação, quadrupedia, ajoelhado, semiajoelhado e bipedestação, na seqüência do desenvolvimento motor. Para isto, foram utilizadas ordens claras e brinquedos como incentivo. Nesta avaliação foram observados parâmetros quantitativos como a capacidade de adotar e manter a postura e, como parâmetro qualitativo, a independência e alinhamento postural.

Quadro IV - Escala de Avaliação das Atividades Funcionais Estáticas (sedestação, quadrupedia, ajoelhado, semi-ajoelhado e bipedestação). Fonte: Durigon e Sá (2004).

\begin{tabular}{|c|l|}
\hline GRAU & Adoção e manutenção da postura \\
\hline 0 & não realiza a atividade funcional \\
\hline 1 & adota a postura com auxílio, mantém com apoio e sem alinhamento \\
\hline 2 & adota a postura com auxílio, mantém com apoio e com alinhamento \\
\hline 3 & adota a postura com auxílio, mantém sem apoio e sem alinhamento \\
\hline 4 & adota a postura com auxílio, mantém sem apoio e com alinhamento \\
\hline 5 & adota a postura sem auxílio, mantém com apoio e sem alinhamento \\
\hline 6 & adota a postura sem auxílio, mantém com apoio e com alinhamento \\
\hline 7 & adota a postura sem auxílio, mantém sem apoio e sem alinhamento \\
\hline 8 & adota a postura sem auxílio, mantém sem apoio e com alinhamento \\
\hline 9 & adota a postura sem auxílio, mantém sem apoio e realiza atividades na postura mantendo o alinhamento \\
\hline
\end{tabular}

A avaliação de tônus, força muscular e atividades funcionais foi aplicada em dois momentos, antes e após três meses de intervenção fisioterapêutica.

3. Protocolo de tratamento

O protocolo de tratamento foi através do Conceito Neuroevolutivo Bobath, cujo alvo principal é auxiliar a criança a mudar suas posturas e movimentos anormais de modo que possam se adaptar confortavelmente ao ambiente e desenvolver uma melhor qualidade nas habilidades funcionais. Foram realizados 3 meses de atendimentos, no período de setembro a novembro de 2007 , duas vezes por semana, com duração de 40 minutos cada terapia, totalizando 25 atendimentos.

A PC apresenta uma desordem de movimento e postura. Assim, no conceito Bobath é utilizado o termo padrões de movimentos e postura. E o conceito se baseia em controlar, modificar os padrões de movimento e postura inadequados, levando a criança exercer o movimento mais próximo do normal possível. Isso pode ser feito a partir de uma postura adotada pela criança, por exemplo, a postura ajoelhada com a extensão de pelve, e esta pode ser modificada para a postura de semi-ajoelhada com alinhamento corporal. São movimentos ativos e controlados pelo terapeuta com o objetivo de mobilizar ativamente articulações, controlar tônus e aumentar força muscular. Outra forma de atuação é promovendo o dinamismo dentro da mesma posição, ou seja, na postura ajoelhada com alinhamento podem ser trabalhadas rotações de tronco, auxiliando no controle postural e demonstrando para as crianças diferentes possibilidades funcionais, como o alcance, por exemplo. E assim, alongar e fortalecer cadeias musculares ${ }^{11}$.

O tratamento teve como objetivos a mobilização e controle de cintura pélvica, fortalecimento e controle de tronco, mobilização, alongamento e fortalecimento de grupos musculares dos quadris, joelhos e tornozelos. Como também o controle de posturas estáticas, melhoria de habilidades funcionais nestas posturas, além de mudanças de posturas.

\section{RESULTADOSE DISCUSSÃO}

Os resultados obtidos referentes ao tônus e força muscular e as atividades funcionais estáticas e dinâmicas, durante a avaliação e reavaliação seguem abaixo, na ordem dos pacientes A, B, C, D.

Os resultados do paciente $\mathrm{A}$ referentes ao tônus e à força da musculatura de membros inferiores (direito e esquerdo) mostraram diminuição do tônus muscular, após o tratamento, com escore de 2 para 1. Os grupos musculares foram: flexores de quadris, adutores de quadris, abdutores de quadris, rotadores mediais e flexores de joelho. Não houve mudança de tônus nos grupos musculares que já apresentavam o escore 1. A força muscular aumentou nos mesmos grupos musculares em que houve diminuição do tônus muscular, mas também nos rotadores laterais de quadris.

O paciente B apresentou diminuição do tônus muscular nos grupos de flexores de quadris, adutores de quadris, rotadores mediais de quadris e flexores de joelho e de tornozelo. Sendo que o escore destes músculos reduziu de 3 para 1, após o tratamento. Os músculos que não obtiveram mudança de tônus apresentavam escore 1 na avaliação inicial. A força muscular aumentou nos grupos de flexores de quadris, adutores de quadris e rotadores mediais de quadris, ou seja, nos mesmos grupos musculares que apresentaram diminuição de tônus muscular com o tratamento.

$\mathrm{O}$ paciente $\mathrm{C}$ teve diminuição do tônus muscular nos grupos de flexores de quadris, adutores de quadris, rotadores 
mediais de quadris e flexores de joelho, extensores de joelho e de tornozelo. $\mathrm{O}$ tônus muscular nestes grupos musculares reduziu de 2 para 1. Não houve alteração nos grupos musculares em que o escore foi de 1 na avaliação inicial. Dentre os músculos que tiveram diminuição do tônus, a força muscular somente não aumentou no grupo de extensores de tornozelo.

Sobre o paciente D, encontrou-se diminuição do tônus muscular nos grupos de flexores de quadris, adutores de quadris, rotadores mediais de quadris e flexores de joelho, extensores de joelho e flexores e extensores de tornozelo. O tônus muscular nestes grupos musculares reduziu de 2 para 1, após o tratamento. Não houve alteração nos grupos musculares em que o escore foi de 1 na avaliação inicial. A força muscular aumentou nos grupos de flexores de joelho extensores de tornozelo, músculos que também tiveram uma diminuição de tônus.

Ao descrever as atividades funcionais dinâmicas e estáticas dos pacientes A, B e C observou-se a melhora nas atividades estáticas de sedestação, quadrupedia e ajoelhado. O paciente D apresentou melhora somente em sedestação e quadrupedia, e este foi o paciente que apresentou aumento de força em um número menor de grupos musculares. Pela escala de atividades funcionais estáticas e dinâmicas, os valores mais expressivos nos pacientes A e C, que apresentaram nas posturas de quadrupedia e ajoelhado o aumento do escore de 1 para 7, após o tratamento. Porém, o paciente B que também teve uma relação entre diminuição de tônus muscular e força muscular, os escores aumentaram de 7 para 8 , na postura de quadrupedia e de 5 para 8 na posição ajoelhada. Cabe destacar que estas eram posturas em que o paciente já apresentava um maior controle. Nas atividades funcionais dinâmicas (engatinhar e marcha), os valores dos escores mantiveram-se os mesmos.

Um músculo com tônus aumentado apresenta encurtamento e consequentemente um número reduzido de sarcômeros, levando a uma diminuição da produção de força adequada para realizar um movimento eficiente. ${ }^{12}$

Estudos em portadores de Paralisia Cerebral demonstram a importância e a eficácia de fortalecimento muscular nesses pacientes, pois além de ganhar força muscular, ocorre uma melhora na função motora. Através de cargas repetitivas de exercícios, ocorrerá um crescimento do volume muscular, devido à hipertrofia das fibras musculares e aumento de unidades motoras dentro de cada sarcômero $^{2,13}$.

Na pesquisa de Liao H.F. et al (2007) ${ }^{14}$, crianças com diplegia espástica apresentaram ligeira melhora em suas habilidades motoras básicas e funcionais, da força muscular e do caminhar com mais eficiência, após a intervenção de um protocolo de fortalecimento muscular.

Em um estudo de Morton J.F., Brownlee M., McFadyen A.K. $(2005)^{15}$, oito crianças com PC foram submetidas a 18 atendimentos fisioterapêuticos. As crianças tiveram a força muscular aumentada em quadríceps e hamstrings. Estas alterações foram mantidas no follow-up. Houve uma diminuição do tônus muscular que continuou a diminuir no follow-up. Atividades como ficar em pé, andar, correr e saltar também tiveram evolução continuada.

Em todos os casos estudados, o padrão de aquisição motora não foi acompanhado de aumento do tono muscular, pelo contrário, houve diminuição deste, o que pode ser atribuído a capacidade de adaptação do fuso muscular a diferentes níveis de demanda através do processo de habituação, facilitada pelo atendimento fisioterapêutico ${ }^{12}$.

Os grupos musculares nos diparéticos espásticos, que apresentam espasticidade e contratura, tem sua principal ação no plano sagital, resultando em padrões e marchas características. Os músculos mais acometidos são: psoas, os "hamstrings", o reto femoral e gastrocnêmico ${ }^{3}$, o que justifica a escolha dos grupos musculares avaliados.

Quanto à avaliação das atividades funcionais estáticas, observamos neste estudo uma melhora descrita pela reavaliação nos quesitos sedestação, quadrupedia e ajoelhado. Vale ressaltar que o controle postural depende de um tônus postural adequado, e este é prejudicado em crianças com diparesia espástica devido a espasticidade encontrada. Porém com a facilitação motora, o tônus e o controle postural são modificados, tendo como conseqüência uma maior variedade de habilidades funcionais ${ }^{7}$.

Para Damiano, D.L. e Abel, M.F. (1998) ${ }^{16}$ a evolução em atividade funcionais, como a marcha, está diretamente relacionada com atividades que exijam força dos pacientes.

Considera-se uma alteração de tono mais significativa quando há uma menor capacidade de adaptação do fuso muscular ao movimento, manifestada pela presença de uma reação ao alongamento variável com a velocidade durante uma parte do arco de movimento ou em todo o arco de movimento, impossibilitando assim a manutenção ou mudanças de posturas $^{10}$. Como ocorreu uma adequada modulação do tônus muscular, melhorando a capacidade de adaptação do fuso muscular, houve condições adequadas para o fortalecimento muscular.

Ao considerar as capacidades motoras dessas crianças, as demandas da tarefa e as características do ambiente, observase que, muitas vezes, o padrão de locomoção apresentado por elas representa a melhor solução possível. Entretanto, algumas dessas soluções funcionais podem colocá-las em situação de risco para futuras alterações estruturais com aparecimento de encurtamentos, deformidades e prejuízo futuro na dinâmica da marcha ${ }^{12}$.

As características não neurais utilizam-se de alongamentos e contrações do músculo (plasticidade muscular), permitindo um melhor alinhamento biomecânico resultando em produção de força mais eficiente. Na questão da característica neural, os Padrões influenciando tônus (PIT's), alteram reflexos cutâneos e proprioceptivos, inicialmente recrutando o sistema de feedback e a longo prazo o sistema de 
feedforward. Os PIT's são aplicados para produzir modificações no corpo inteiro (uso de pontos chaves mais proximais), ou mobilizações específicas bem localizadas ${ }^{7}$.

Knox V. e Evans A.l. (2002) ${ }^{17}$ realizaram uma pesquisa que teve como objetivo de avaliar os efeitos funcionais do conceito Bobath. Quinze crianças com PC com idades com a média de idade de 7 anos e 4 meses foram submetidas ao tratamento baseado pelo conceito Bobath. Estas crianças tiveram importante evolução em relação a função motora.

\section{CONCLUSÃO}

Concluindo, é na limitação funcional, ou seja, durante o desempenho de atividades e tarefas da rotina diária que a incapacidade da criança émanifestada. Todas as argumentações feitas na teoria sobre a influência do tônus e da força muscular e sua correlação com as atividades funcionais, foram demonstradas neste estudo onde podem-se afirmar que houve uma diminuição do tônus e aumento da força muscular com uma conseqüente melhora das atividades funcionais estáticas nos pacientes com diparesia espástica após intervenção fisioterapêutica através do Conceito Neuroevolutivo Bobath.

\section{REFERÊNCIAS BIBLIOGRÁFICAS}

1. Leite JMRS, Prado GF. Paralisia cerebral aspectos fisioterapêuticos e clínicos. Rev. Neurociências 2004; 12: 42-45.

2. Bache CE, Selber P, Graham H K. The management of spastic diplegia. Currentorthopaedics 2003; 17: 88- 104.

3. Cargnin AM, Carla M. Proposta de tratamento fisioterapêutica para crianças portadoras de paralisia cerebral espástica, com ênfase nas alterações musculoesqueléticas. Rev Neurociências 2003; 11 : 34-39.

4. Bear MF, Connors BW, Paradiso M A. Neurociências, desvendando o sistema nervoso. São Paulo: 2 ed, artmed, 2002.

5. Peixoto ES, Mazzitelli C. Avaliação dos principais déficits e proposta de tratamento da aquisição motora rolar na paralisia cerebral

\section{$2004 ; 12$.}

6. Bobath B, Bobath K, Desenvolvimento Motor nos Diferentes Tipos de Paralisia Cerebral, 1 ed. São Paulo, Manole, 1989.

7. The Bobath Approach. London: The Bobath Centre for children with cerebral palsy. (citado em 01/12/2007). Disponível em: http://www.bobath.org.uk/.

8. Teive HAG, Zonta M, Kumagai Y. Tratamento da espasticidade: Uma atualização. Arq Neuropsiquiatr 1998; 56(4): 852-858.

9. Reese, N. B. Testes de função muscular e sensorial. Rio de Janeiro: Guanabara Koogan,

2000.

10. Durigon O F; Sá C.S.S; Sitta, L V. Validação de um protocolo de avaliação do tono muscular e atividades funcionais para crianças com paralisia cerebral. Rev.Neurociências 2004; 87 93.

11. The Bobath Centre. Notes to accompany the 8-week course in cerebral palsy. Londres, 1997.

12. Cury VCR, Mancini MC, Melo AP, Fonseca ST, Sampaio RF, Tirado MGA. Efeito do uso da órtese na mobilidade funcional de crianças com Paralisia Cerebral. Rev. Brás. Fisioter 2006;

13. Rosenbaum PL, Russel D J, Cadman, D. T.; Gowland C, Jarvis S, Hardy S. Measuring Change in Motor Function In Children with Cerebral Palsy: A Special Communication. Phys. Ther 1990; 70: 125-131.

14. Liao HF, Liu YC, Liu WY, Lin YT. Effectiveness of loaded sit-to-stand resistance exercise forchildren with mild spastic diplegia: a randomized clinical trial. Arch Phys Med Rehabil. 2007 88(1):25-31.

15. Morton, JF, Brownlee, M. McFadyen, AK. The effects of progressive resistance training for children with cerebral palsy. Clin. Rehabil. 19(3):283-289.

16. Damiano DL, Abel MF. Functional outcomes of strength training in spastic cerebral palsy. Arch Phys Med Rehabil. 1998, 79(2):119-125.

17. Knox, V, Evans, AL. Evaluation of the functional effects of a course of Bobath therapy in children with cerebral palsy: a preliminary study. Dev Med Child Neurol. 2002, 44(7):447460 .

Endereço para correspondência:

Aneline Maria Ruedell

Rua Pinheiro Machado, 2866/302

97050-600 Santa Maria RS - Brasil

Fone: 3026-8268. E-mail: aneruedell@yahoo.com.br 